\title{
Urinary tract infections during pregnancy - clinical picture and therapeutic approach in the Infectious Diseases Hospital of laşi (2009-2012)
}

\author{
Mihaela Cătălina Luca 1*, Andrei Vâță', Olivia Dorneanu², Jugănariu Gabriela², Carmen Dorobăț ${ }^{1}$ \\ From The 9th Edition of the Scientific Days of the National Institute for Infectious Diseases Prof Dr Matei Bals \\ Bucharest, Romania. 23-25 October 2013
}

\section{Background}

Urinary tract infections in pregnancy represent one of the significant pathologies that can influence both the health of the mother and of the child, often giving rise to a polymorphic clinical picture and posing therapeutic difficulties, due to antibiotic resistance and drug toxicity.

\section{Methods}

We performed a retrospective study on 60 pregnant patients, diagnosed with urinary infections in the Clinic Hospital of Infectious Diseases of Iaşi, between January 2009 and December 2012.

\section{Results}

The annual number of the admissions was relatively constant, except for the year 2010 with 25 cases; the infections were more frequent in 26-40 years old pregnant women (63.3\%), during the first (38.3\%) and the second trimester of pregnancy (48.3\%) and in primiparous women (61.7\%). Fever was present in $71.7 \%$ of the patients, $51.7 \%$ having also digestive symptomatology. The inflammatory syndrome was illustrated at admission through leukocytosis (in $66.7 \%$ cases), high values of ESR (88.9\% cases), and of fibrinogen (31\% of cases). Pyuria was present in $75 \%$ of cases, and in $25.7 \%$ were associated albuminuria. $65 \%$ cases were considered lower urinary tract infections. The etiology was established in $73.3 \%$ cases, being dominated by E coli (88.3\%); also implicated were: Klebsiella spp. (6.7\%), Streptococcus spp. (1.7\%), Candida 3.3\%. The etiologic treatment was based on beta-lactams, especially in association with beta-lactamase inhibitors: amoxicillin-clavulanate - 43.3\%, ampicillin-sulbactam - 3.3\%, second generation

"Gr.T.Popa" University of Medicine and Pharmacy, Iaşi, Romania Full list of author information is available at the end of the article cephalosporins $-16.7 \%$ or third generation cephalosporins (18.3\%) and carbapenems - 10\%. The evolution was favorable in all the cases, with no immediate negative effects on the baby.

\section{Conclusion}

The urinary tract infections were more frequent during the first months of pregnancy, in primiparous women older than 26 years old, the etiology being dominated by $E$ coli with a decreased antibiotic susceptibility in the last years.

Authors' details

"Gr.T.Popa" University of Medicine and Pharmacy, laşi, Romania. ${ }^{2}$ Infectious Diseases Hospital laşi, Romania.

Published: 16 December 2013

doi:10.1186/1471-2334-13-S1-09

Cite this article as: Luca et al:: Urinary tract infections during pregnancy - clinical picture and therapeutic approach in the Infectious Diseases Hospital of laşi (2009-2012). BMC Infectious Diseases 2013 13(Suppl 1):09.

Submit your next manuscript to BioMed Central and take full advantage of:

- Convenient online submission

- Thorough peer review

- No space constraints or color figure charges

- Immediate publication on acceptance

- Inclusion in PubMed, CAS, Scopus and Google Scholar

- Research which is freely available for redistribution 